\title{
Identifying very low-risk STEMI patients for early ICU discharge in the COVID-19 era
}

\author{
Omar Abdul-Jawad Altisent ${ }^{1,2} \cdot$ Xavier Carrillo $^{1,2} \cdot$ Rishi Puri $^{3} \cdot$ Antoni Bayés-Genís $^{1,2}$
}

Received: 1 June 2020 / Accepted: 30 June 2020 / Published online: 13 July 2020

(c) Springer-Verlag GmbH Germany, part of Springer Nature 2020

Keywords STEMI · Primary percutaneous coronary intervention · COVID-19

Sirs:

Assessment of individual patient risk for short-term outcomes following acute ST-elevation myocardial infarction (STEMI) has focused on risk scores with high sensitivity to identify high-risk patients [1]. By contrast, there is a lack of uniformly accepted scores for predicting the absence of complications following primary percutaneous intervention (pPCI), and current guidelines still recommend admission in intensive care unit (ICU) during at least $24 \mathrm{~h}$ after symptoms onset in patients with uncomplicated STEMI [1-3]. Minimizing ICU admissions, particularly in the current COVID19 era, is paramount for minimizing patient exposure and optimizing resource allocation [4-6].

We hypothesized whether in the era of regional pPCI reperfusion networks, uncomplicated STEMI patients remaining event-free following prompt TIMI 3 flow restoration, would facilitate early discharge from the ICU $[7,8]$. The present study aimed to identify predictors of very low-risk STEMI patients following uncomplicated pPCI, and to assess the safety of an early ICU discharge strategy.

To test our hypothesis, we analyzed consecutive STEMI patients undergoing pPCI in our referral area $(\sim 850,000$ inhabitants) arriving within $12 \mathrm{~h}$ after symptom onset, between 2012 and $2019(n=2185)$. Per protocol all patients received a loading dose of $300 \mathrm{mg}$ of aspirin plus $600 \mathrm{mg}$ of clopidogrel or $180 \mathrm{mg}$ of ticagrelor or $60 \mathrm{mg}$ of prasugrel

Omar Abdul-Jawad Altisent

oabduljawadaltisent@gmail.com

1 Germans Trias I Pujol University Hospital, Universitat Autònoma de Barcelona, Carretera de Canyet s/n, 08916 Badalona, Barcelona, Spain

2 CIBERCV, Madrid, Spain

3 Cleveland Clinic, Cleveland, OH, USA before the procedure. We recorded in a prospective dedicated database clinical characteristics, peri-procedural complications including arrhythmias, Killip-Kimball class, reperfusion time, and procedural characteristics; 24-h ICU cardiac complications including ventricular fibrillation/tachycardia, A-V block or asystole, acute pulmonary edema, mechanical ventilation, shock, acute stent thrombosis and cardiac death; and 30-day cardiac death. Patients were divided in two cohorts: a derivation cohort ( $n=1492$; years 2012-2016) to identify independent very low-risk predictors; and a validation cohort ( $n=693$; years 2017-2019).

Univariate and multivariate logistic regression analysis were used to determine predictors of 24-h cardiac complications and 30-day cardiac death. Multivariate analysis included clinical and procedural predictors that exhibited a $p$ value $<0.05$ in the univariate analysis. First, multivariableindependent predictors allowed patient stratification in to very low-risk (odds ratio $\leq 0.85$ for early cardiac complications and 30-day cardiac death) and other risk groups. Next, cardiac events beyond the first $6 \mathrm{~h}$ in the ICU were characterized in the very low-risk group. Finally, specificity to predict early cardiac complications and 30-day cardiac death in the very-low risk group was also assessed.

Derivation cohort independent predictors of very lowrisk were age $\leq 75$ years-old, absence of primary malignant arrhythmias during the first assistance, Killip-Kimball class I, radial access, absence of left main or three-vessel coronary disease, and successful angioplasty-stenting (defined as final TIMI 3 flow), as shown in Table 1 . The same very low-risk predictors emerged in the validation cohort (data not presented).

In the derivation cohort, 144 of $1492(9.7 \%)$ patients had a 24-h-cardiac event (21 patients with stent thrombosis); 50 (3.4\%) suffered a 30-day cardiac death; and $638(43 \%)$ met very-low risk criteria. In the very-low-risk group, seven patients (1.1\%) had a 24 -h-cardiac event, all 
Table 1 Univatiate and multivariate analysis of predictors of very low-risk of 24-h cardiac events and 30-day cardiac death following primary percutaneous coronary intervention

\begin{tabular}{|c|c|c|c|c|c|c|c|}
\hline Clinical and procedural predictors & $\begin{array}{l}\text { No complica- } \\
\text { tion }(n=1348)\end{array}$ & Complication $(n=144)$ & $p$ & $\begin{array}{l}\text { Early complica- } \\
\text { tion* [OR, } 95 \% \\
\mathrm{CI}]\end{array}$ & $p$ & $\begin{array}{l}\text { 30-day cardiac } \\
\text { death [OR, 95\% } \\
\text { CI] }\end{array}$ & $p$ \\
\hline Age $\leq 75$ year old & $1074(80)$ & $88(61)$ & $<0.01$ & $0.56[0.37-0.84]$ & $<0.01$ & $0.10[0.04-0.20]$ & $<0.01$ \\
\hline Female gender & $296(22)$ & $41(29)$ & 010 & & & & \\
\hline Diabetes mellitus & $328(24)$ & $44(31)$ & 0.12 & & & & \\
\hline Previous vascular disease (any) & $274(20)$ & $43(30)$ & 0.01 & & & & \\
\hline Anterior myocardial infarction & $546(41)$ & $75(52)$ & 0.01 & & & & \\
\hline Killip class I at presentation & $1179(88)$ & $59(41)$ & $<0.01$ & $0.14[0.10-0.22]$ & $<0.01$ & $0.12[0.06-0.26]$ & $<0.01$ \\
\hline No arrhythmia first assistance ${ }^{\dagger}$ & $180(13)$ & $59(41)$ & $<0.01$ & $0.32[0.21-0.21]$ & $<0.01$ & $0.36[0.17-0.76]$ & $<0.01$ \\
\hline Radial access & $1320(98)$ & $125(87)$ & $<0.01$ & $0.50[0.24-1.04]$ & 0.06 & $0.18[0.07-0.46]$ & $<0.01$ \\
\hline No three vessel/LM disease & $283(21)$ & $46(32)$ & $<0.01$ & $0.85[0.56-1.30]$ & 0.40 & $0.51[0.25-1.00]$ & 0.05 \\
\hline Stent implanted & $1321(98)$ & $144(100)$ & 0.20 & & & & \\
\hline Successful angioplasty-stenting ${ }^{\ddagger}$ & $1263(94)$ & $121(84)$ & $<0.01$ & $0.42[0.10-0.21]$ & $<0.01$ & $0.16[0.07-0.37]$ & $<0.01$ \\
\hline Complete revascularization & $519(39)$ & $46(32)$ & 0.16 & & & & \\
\hline Reperfusion time (minutes) & $191(130-309)$ & $181(129-299)$ & 0.60 & & & & \\
\hline $\mathrm{IIb} / \mathrm{IIIa}$ inhibitors use & $547(41)$ & $50(34)$ & 0.36 & & & & \\
\hline Dual antiplatelet load & $1348(100)$ & $144(100)$ & NA & & & & \\
\hline Baseline oral anticoagulation & $44(3)$ & $12(8)$ & 0.02 & & & & \\
\hline \multicolumn{8}{|l|}{ ICU cardiac predictors** } \\
\hline $\mathrm{LVEF}<40 \%$ & $1166(86)$ & $77(54)$ & $<0.001$ & NA & & NA & \\
\hline Creatinin clearance (ml/min) & $92(42)$ & $68(38)$ & $<0.001$ & NA & & NA & \\
\hline
\end{tabular}

Values presented as $n(\%)$ or mean (SD) or median (Q1-Q3)

$I C U$ intensive care unit, $N A$ not assessed, $L M$ left main, $L V E F$ left ventricular ejection fraction

*Including 24-h cardiac death, malignant arrhythmias, severe heart failure, stent thrombosis/re-acute myocardial infarction

**Intensive Care Unit predictors were not included in the multivariate analysis

${ }^{\dagger}$ Including atrial or ventricular fibrillation, ventricular tachycardia, A-V block or asystole appeared until the end of primary percutaneous coronary intervention procedure

${ }^{\ddagger}$ Defined as final TIMI 3 flow without major procedural complications

due to stent thrombosis, one with concomitant ventricular fibrillation (specificity $=0.95, p<0.01$ ). No 30-day cardiac deaths were recorded in the very low-risk group (specificity $=1, p<0.01)$.

In the validation cohort, 78 of $693(11.3 \%)$ patients had a 24 -h-cardiac event (16 of them stent thrombosis); 17 (2.5\%) suffered a 30-day cardiac death; and 369 (53\%) met criteria of very-low risk. In the very-low risk group, ten patients $(2.7 \%)$ had a 24 -h-cardiac event, nine due to stent thrombosis, (one with concomitant ventricular fibrillation) and one due to heart failure (patient with active hemolytic anemia complicated with systemic inflammatory syndrome) (specificity $=0.88, p<0.01$ ). No 30-day cardiac deaths were recorded in the very low-risk group (specificity $=1, p<0.01)$.

The 6-h ICU cut-point analysis performed in the verylow risk group only revealed one stent thrombosis event beyond the $6 \mathrm{~h}(0.9 \%$ ), without other complications (specificity $\approx 1, p<0.01$ ).
This is the first study to focus on predictors of very lowrisk of complications following STEMI in the pPCI reperfusion era. We found that younger patients with uncomplicated STEMI without complex coronary anatomy are highly likely to remain uncomplicated providing the infarct related artery is successfully opened via transradial pPCI. Importantly, the identified variables may be easily recorded upon completion of the pPCI procedure. Proper identification of such very low-risk patients should improve current post-procedural decision-making algorithms, including very early (within $6 \mathrm{~h}$ ) patient transfer from the intensive care to a conventional ward, thus optimizing intensive care resources for other lifethreatening pathologies.

Stent thrombosis is always concerning, and in this verylow risk stratification model, it was the least accurate event to predict; nevertheless, stent thrombosis usually manifests early post-pPCI. Indeed, only one patient presented stent thrombosis beyond $6 \mathrm{~h}$ after ICU admission. These data should be interpreted in the context of a regional pPCI reperfusion network that includes a high percentage of radial 
access and stenting, and short reperfusion delay [2]. Nevertheless, pending confirmation in larger prospective studies, an early discharge strategy from the ICU within $6 \mathrm{~h}$ postsuccessful pPCI may be a reasonably safe option in almost half of STEMI patients.

\section{References}

1. Ibanez B, James S, Agewall S et al (2018) 2017 ESC guidelines for the management of acute myocardial infarction in patients presenting with ST-segment elevation: the task force for the management of acute myocardial infarction in patients presenting with ST-segment elevation of the European Society of Cardiology (ESC). Eur Heart J 39:119-177

2. Halkin A, Singh M, Nikolsky E et al (2005) Prediction of mortality after primary percutaneous coronary intervention for acute myocardial infarction: the CADILLAC risk score. J Am Coll Cardiol 45:1397-1405

3. De Luca G, Suryapranata H, van't Hof AW et al (2004) Prognostic assessment of patients with acute myocardial infarction treated with primary angioplasty: implications for early discharge. Circulation 109:2737-2743

4. Abdi S, Salarifar M, Mortazavi SH et al (2020) COVID-19 sends STEMI to quarantine!? Clin Res Cardiol. https://doi.org/10.1007/ s00392-020-01664-3(Epub ahead of print)

5. Grasselli G, Pesenti A, Cecconi M (2020) Critical case utilization for the COVID-19 outbreak in Lombardy, Italy. JAMA. https:// doi.org/10.1001/jama.2020.4031(Epub ahead of print)

6. Böhm M, Frey N, Giannitsis E, Sliwa K et al (2020) Coronavirus disease 2019 (COVID-19) and its implications for cardiovascular care: expert document from the German Cardiac Society and the World Heart Federation. Clin Res Cardiol. https://doi. org/10.1007/s00392-020-01656-3(Epub ahead of print)

7. Kammler J, Kypta A, Hofmann R et al (2009) TIMI 3 flow after primary angioplasty is an important predictor for outcome in patients with acute myocardial infarction. Clin Res Cardiol 98(3): 165-170

8. Zahler D, Lee-Rozenfeld K, Ravid D et al (2019) Relation of lowering door-to-balloon time and mortality in ST segment elevation myocardial infarction patients undergoing percutaneous coronary intervention. Clin Res Cardiol 108(9):1053-1058 